\title{
Culture and Classification in Markets: An Introduction
}

\author{
Ronald L. Breiger \\ Department of Sociology, University of Arizona \\ Tucson, AZ 85721-0027, USA
}

\begin{abstract}
Recent work at the boundary of culture and the economy focuses on relations between meaningful subjectivity and macro-level structure. This special issue features new directions in the study of culture and classification in markets, including research on vocabularies of organizing, cross-national comparisons of market identities, development of metrics and theory for assessing the recognition of market rivals by one another, and relational techniques for the identification of meaningful action in complex corporate fields. Classical concerns with these broad areas provide a means of situating the contemporary work. The new work also has some implications for unifying the study of power, politics, and culture in institutional analysis.
\end{abstract}

The work of art interprets the meaning of the phenomenon itself. At the turn of the last century Georg Simmel took this proposition merely as a point of departure for his discussion of culture insofar as it relates to analysis of the modern economy. The paradox, as Simmel ([1900] 1978: 447) points out, is that in order to interpret the meaning of the phenomenon itself, "everything depends on discovering the meaning and secret of things in order to represent them in a form that is purer and clearer than their natural development." The artistic ideal is to present the object in its unique significance ("l'art pour l'art"). But the cultural ideal is different: here the goal is to transcend and integrate various types of value (aesthetic, ethical, religious, and so on) "from the standpoint of the development of our energies or our being beyond the degree 
considered to be purely natural." Thus, in refining objects, we create them in our own image, and by cultivating objects (that is, "by increasing their value beyond the performance of their natural constitution"), we cultivate ourselves (p. 447). The modern economy is the arena par excellence for the cultivation of objects, indeed for the objectification of objects. Therefore analysis of markets and economies benefits mightily from an understanding of "the relationship that exists between the division of labor and objectification of culture" (p. 458). Simmel's primary insight in The Philosophy of Money was to recognize money "as a symbol" of "the behavior of objects" (pp. 511-12).

Social theory in fact offers a variety of useful starting points for the analysis of culture and classification as these pertain to markets and the economy. Marx theorized the fetishism of commodities as arising because "the relation of the producers to the sum total of their own labour is presented to them as a social relation, existing not between themselves, but between the products of their labour" (Marx [1867 ] 1906: 83); every commodity is thus a "social hieroglyphic" that is "as much a social product as language" and that we may try to "decipher" (p. 85). A writer of our own time, Miranda Joseph, argues that many social formations, from voluntary associations to business enterprises, might be analyzed on the model of fetishism; for example, communities created through labor or participation subsequently appear to be "independent, organic entities over and against the subjects who produced them" (Joseph 2002:57), generating a pervasive ideology of the "romance of community." Moreover, an important line of contemporary research has stemmed from "an unexpected convergence between Marx and Simmel on the topic of commodities," leading to the theorizing of cultural perspectives on commodities as expressed for example in the volume, The Social Life of Things (Appadurai 1986, quoting p. 7). Cultural perspectives can also deeply enrich analyses of 
business practices and financial mechanisms, as in Carruthers and Espeland's (1991) valuable critique and extension of the writing of Weber, Sombart, and Schumpeter on the method of double-entry bookkeeping, in which the authors develop the rhetorical as well as the technical dimensions of accounting methods, insisting that "to provide an account is to provide a classificatory scheme" (p. 55).

In their study of so-called primitive classification, Durkheim and Mauss ([1903] 1963) articulated the proposition that systems of classification are fundamental to social organization. Likewise, Lévi-Strauss ([1949] 1967: 32) wrote that "the prime rôle of culture" is "to replace chance by organization," and Lévi-Strauss's study of the prohibition of incest in classical Australian societies led him to formulate a theory according to which systems of restricted and generalized exchange and purchase were inseparable from interlocking classifications of types of group (such as clans and classes) and objects that are exchanged (such as wives and children). In the striking phrase of Mary Douglas (1986: 97), "the sacred for Durkheim and Mauss was nothing more mysterious and occult than shared classifications, deeply cherished and violently defended." In a brief discussion of markets, Douglas writes (p. 108) that new institutions come into existence, and the institutions make new labels, and the labels make new kinds of people. For example, Douglas writes, dictionaries of French textile institutions show that classifications emanating from administrative institutions have a territorial base, while those produced by manufacturing institutions focus on production. What the classifications are devised for and what they can and cannot do are different in each case. "A classification of classificatory styles would be a good first step towards thinking systematically about distinctive styles of reasoning" (Douglas 1986: 108). Or as Bourdieu ([1986] 1990: 132) put it, agents 
'classify themselves by choosing, in the space of available goods and services, goods which occupy a position in this space homologous to the position they occupy in social space. This means that nothing classifies somebody more than the way he or she classifies.'

In order to highlight the range of incisive and exciting contemporary research at the intersection of culture and the economy, Marc Schneiberg organized a session on "Culture and Classification in Markets" at the 2004 annual meeting of the American Sociological Association. This special issue of Poetics features revised versions of the papers presented at that session, at which I was privileged to serve as discussant. These papers may be read as pushing the boundary between cultural sociology and one of its publics (Jacobs and Spillman, 2005), the study of markets. I will briefly introduce each of the papers.

William Ocasio and John Joseph study the evolution of vocabularies of corporate governance over the past three decades in the United States, with reference to cultural adaptation and institutional change. First used in the early 1970s in the context of corporate scandal and directors' liabilities, meanings attributed to the phrase "corporate governance" have ranged across domains of corporate reform, democratic governance, shareholder rights, and a more narrow, technical and specialized conception of a board's relations with the chief executive officer and the shareholders (among other meanings) as the term has become institutionalized. The present inquiry relies on three types of procedure: content analysis of newspaper articles, historical analysis of government and business sources, and inductive interpretation of key publications on corporate governance. Ocasio and Joseph formulate an evolutionary theory of cultural adaptation for new market-oriented vocabularies. This paper provides an impressive 
exemplar for the operational study of the interplay of meaning, organizational fields, and the institutionalization of lexical networks or "vocabularies" that "socially canalize thought," in the words of C. Wright Mills (1939: 678), whose early work provides important theoretical inspiration for the paper by Ocasio and Joseph. In particular, Mills (1939), who acknowledged being influenced in this regard by G.H. Mead and by C.S. Peirce, contrasts the formal principles of logic (and laws of proof) with a social logic that is conversational in nature and that operates "from the standpoint of a generalized other." Thus Mills can write that "problems set by one logic are, with a change in interests, outgrown, not solved" (p. 674). Mills is thus a genuine precursor of the concept of institutional logics (see Mohr, 2000: 62-66 for a review) that is used widely in contemporary cultural and institutional studies and by several authors of papers in this special issue.

Wei Zhao compares the classification systems that organize, respectively, the American and French wine industries, thus bringing new research to bear on Mary Douglas's (1986: 10409) discussion of this topic. Beginning with 62 California wineries and 56 French wineries whose wines were among the "Top 100" in 1997-98 according to a standard industry source, Zhao collected data on all their wines (4,894 California wines; 3,795 French wines) in order to populate the two different classification systems. Zhao illustrates how differences in the basis of classification (by an elaborate, but horizontal, system of grape variety in California; by a less elaborate, but strongly vertical, system of appellation and region in France) control the identity of a bottle of wine and also its consumer in characteristically different ways. Zhao shows how the boundaries created by classification signify social standing, even in the American system of horizontal categories. And he is attentive to the political struggles of interested wineries, distributors, and other market actors in shaping or modifying the internal boundaries of the 
classification. Zhao's paper is also valuable for reviewing a great deal of the contemporary research on culture and classification, focusing especially on work relevant to economic markets. Mark Kennedy presents theorization and a well-elaborated empirical investigation of the construction of categories in new product markets. His paper's title, "Behind the One-Way Mirror," refers to a key idea of Harrison White's (2002) theory of production markets, according to which a collectively defined schedule of producers' identities with respect to the cost and quality of their products - a schedule that culture scholars would recognize as an example of the commensuration (Espeland and Stevens, 1998) on which markets and other social fields depend (see also Stinchcombe, 2002) — arises from the monitoring of producers' publicly observable commitments on the part of other producers in the market. White uses the metaphor of a oneway mirror because the producers watch each other carefully but without being able to observe consumers' behavior, even though the buyers can see the producers. What is behind this mirror, Kennedy asks, or what does the mirror (or the metaphor) hide? In practice, how do rivals identify one another as a new market begins to take form?

Kennedy's basic answer is that media stories, "the most public of discourses," provide crucial shape to new categories of actor and demand. This paper advances a perspective that sees discourse as a principal medium of market construction (see also Muetzel, 2005; for a comparative case, consider how reviewers reach consensus on the value of literary works; van Rees, 1987, developing Bourdieu's theory of the art field). The theory is formulated as an interrelated set of hypotheses, which are applied in a study of the then-new market for computer workstations in the decade of the 1980s. Working with a media archive of 28,292 stories and press releases on computer workstations, Kennedy developed software to extract associations among terms known to be instances of the new market category. Many of his specific analyses 
derive from a firm-by-firm co-mention matrix. A key measure is the average release density (ARD), the average number of rivals mentioned in a firm's press releases for a given period (quarter). Among the key findings is that, as producers find each other in the media, those that publicly recognize the rivals they find do better for it. Kennedy's interpretation is that producers that persistently ignore their rivals "end up cursed with what they want: to be in a class by themselves." To my mind, again with reference to Espeland and Stevens (1998), this finding of Kennedy's suggests a pathology of distinction: that innovation that breaks the bounds of commensurability can easily be counterproductive.

The paper by Klaus Weber that concludes this special issue is, at one level, a study of the content of 943 letters to shareholders in the annual reports of 94 German and US companies in the pharmaceutical sector. More generally, however, Weber is concerned with how meaningful elements (such as images of the corporation as a thoughtful system, a taker of risks, and/or a portfolio of businesses) combine into toolkits (pragmatic culture-in-use; Swidler, 2001). The large, multinational fields that Weber seeks to model are characterized by complexity, diversity and relatively unstructured cultural resources. He sees "the key challenge for quantitatively inclined analysts of culture at the toolkit level" as identifying the segments of meaning that will be the units of analysis, and in reducing the complexity of these sets. With respect to the methods most widely deployed to measure meaning structures (Mohr, 1998), Weber outflanks them on two different sides. First, as mentioned, his focus is not on cultural systems and their deep structure, but rather on toolkits. Second, in his distinctive formulation of operational quantitative procedures, Weber brings to bear ideas and analytic tools primarily drawn from semiotics (in fact, from two very different semioticians, Barthes and Greimas). ${ }^{1}$ The inductively

\footnotetext{
${ }^{1}$ To mention just one difference between the two semioticians: Greimas was strongly influenced by the "radically structuralist linguistics" of Louis Hjelmslev and focused essentially exclusively on text semiotics, whereas Barthes
} 
constructed result of these procedures, referred to as a repertoire space and as a register of cultural elements, is a nested category system (Table 1) consisting of six environmental domains, 35 pairs of logical oppositions, and 63 empirically observable cultural elements. Profile similarity at the firm level, as well as relations among the firms based on their profiles, is assessed at various points in time. One of the strong findings (see Figure 3, where lines are drawn around the US firms) is that nationality organizes this pharmaceutical field strongly in 1980 , but essentially not at all by 2000 . In addition to his primary focus on how to extract categories from texts by means of automated tools rooted in semiotics, Weber's paper also illustrates the relationality that characterizes much recent work on classification and boundary systems (see the review in Lamont and Molnár, 2002:169).

I would like to conclude these introductory comments by giving, not the last word but the penultimate comment, to Marc Schneiberg, the organizer of the conference session on which these papers are based. Schneiberg and Tim Bartley write that the cognitive or cultural turn, especially as it has been characteristic of an important approach to institutionalism in sociology (DiMaggio and Powell, 1991), has been much too avoiding of the political dimension. State policies and organizational forms have been seen as expressions of taken-for-granted models of order, or as the results of diffusion processes based on mimicry or mimesis. What is needed, according to Schneiberg and Bartley (2001: 135-36), is a "more political and contested view of institutional factors, highlighting how political and institutional processes fundamentally define and transform the choice sets available for private and public problem-solving behavior" (see also Lounsbury and Rao, 2004, on the political nature of markets and the often-decisive role of powerful actors). 
While acknowledging the key insight of these writers who regret the general apolitical nature of cultural analyses of markets, I would also point out that it is possible to combine political and cultural analyses of classification, as in, for example, Wei Zhao's article in this issue, Pedriana and Stryker's (1997) study of affirmative action law, and indeed Schneiberg and Bartley's (2001) study of fire insurance regulation. Second and more to the point of this special issue: Suppose that a qualitatively different family of analyses is needed to move up to the next level in our understanding of power and politics. Consider the possibility that a realistic comprehension of interests and power politics may need to focus on the meso-level linkages between meaningful subjectivity and macro-level structure (Jacobs and Spillman, 2005: 12) and may need to involve the formulation of new relational concepts and methods such as vocabularies of organizing (Ocasio and Joseph), metrics and theory for assessing the recognition of competitive rivals by one another (Kennedy), and ability to identify meaningful action in multinational corporate fields of great complexity (Weber). The papers in this special issue point the way to this next level of understanding.

\section{Acknowledgements}

Thanks to Marc Schneiberg for organizing the session at which the papers in this issue were presented, to Kees van Rees for suggesting this special issue and for working effectively and patiently both with the authors and with me to bring it to fruition, and to Linda Waugh for continuing consultation on semiotics and many other areas.

\section{References}

Appadurai, Arjun (Ed.), 1986. The Social Life of Things. Cambridge University Press, Cambridge and New York. 
Bourdieu, Pierre, (1986) 1990. Social space and symbolic power. In: Bourdieu, Pierre, In Other Words: Essays Toward a Reflexive Sociology. Stanford University Press, Stanford, CA (M. Adamson, Trans.), 123-139.

Carruthers, Bruce G., and Wendy Nelson Espeland, 1991. Accounting for rationality: Doubleentry bookkeeping and the rhetoric of economic rationality. American Journal of Sociology 97 (1), 31-69.

DiMaggio, Paul J., and Walter W. Powell, 1991. Introduction. In: Powell, W.W., and DiMaggio, P.J. (Eds.), The New Institutionalism in Organizational Analysis. University of Chicago Press, 1-40.

Douglas, Mary, 1986. How Institutions Think. Syracuse University Press, Syracuse, NY.

Durkheim, Émile, and Marcel Mauss, (1903) 1963. Primitive Classification. University of Chicago Press, Chicago (R. Needham, Trans.).

Espeland, Wendy Nelson, and Mitchell L. Stevens, 1998. Commmensuration as a social process. Annual Review of Sociology, 24, 313-343.

Jacobs, Mark D., and Lyn Spillman, 2005. Cultural sociology at the crossroads of the discipline. Poetics 33 (1), 1-14.

Joseph, Miranda, 2002. Against the Romance of Community. University of Minnesota Press, Minneapolis.

Lamont, Michèle, and Virág Molnár (2002). The study of boundaries in the social sciences. Annual Review of Sociology, 28, 167-195.

Lévi-Strauss, Claude, (1949) 1967. The Elementary Structures of Kinship. Beacon Press, Boston (J.H. Bell and J.R. von Sturmer, Trans.). 
Lounsbury, Michael, and Hayagreeva Rao, 2004. Sources of durability and change in market classifications: A study of the reconstitution of product categories in the American mutual fund industry, 1944-1985. Social Forces, 82 (3), 969-999.

Marx, Karl, (1867) 1906. Capital, vol. I: A Critique of Political Economy. The Modern Library, New York.

Mills, C. Wright (1939). Language, logic, and culture. American Sociological Review, 4 (5), $670-680$.

Mohr, John W. (1998). Measuring meaning structures. Annual Review of Sociology, 24, 345370.

Mohr, John W. (2000). Introduction: Structures, institutions, and cultural analysis. Poetics, 27 (23), 57-68.

Muetzel, Sophie, 2005. Disputes into identities: Analyzing the discursive competition of market actors. Paper prepared for presentation at the American Sociological Association annual meeting, Philadelphia. (Social Sciences Department, Humboldt University, Berlin).

Nöth, Winfried (1990). Handbook of Semiotics. Indiana University Press, Bloomington.

Pedriana, Nicholas, and Robin Stryker, 1997. Political culture wars 1960s style: Equal employment opportunity-affirmative action law and the Philadelphia Plan. American Journal of Sociology, 103 (3), 633-691.

Schneiberg, Marc, and Tim Bartley, 2001. Regulating American industries: Markets, politics, and the institutional determinants of fire insurance regulation. American Journal of Sociology, 107 (1), 101-146.

Simmel, Georg, (1900) 1978. The Philosophy of Money. Routledge \& Kegan Paul, London (T. Bottomore and D. Frisby, Trans.). 
Stinchcombe, Arthur L. (2002). New sociological microfoundations for organizational theory: A postscript. In: Michael Lounsbury and Marc J. Ventresca (Eds.), Social Structure and Organizations Revisited. JAI, Amsterdam, 415-433.

Swidler, Ann (2001). Talk of love: How culture matters. University of Chicago Press, Chicago, IL.

Van Rees, C.J., 1987. How reviewers reach consensus on the value of literary works. Poetics, $16(3-4), 275-294$.

White, Harrison C., 2002. Markets from Networks: Socioeconomic Models of Production. Princeton University Press, Princeton, NJ. 